\title{
Developing a Discriminant Model for Indian FMCG Sector: A Tool to Identify the Sustainable Performance of a Company
}

\author{
${ }^{1}$ L. Philo Daisy Rani and ${ }^{2}$ Mayuresh Jahagirdar \\ ${ }^{1}$ Department of Management Studies, National Institute of Technology, \\ Periyar University, Salam, Tiruchirappalli, Tamil Nadu, India \\ ${ }^{2}$ Department of Production Engineering, University of Pune, \\ Tiruchirappalli, Tamil Nadu, Maharashtra, India
}

\begin{abstract}
The purpose of this study is to distinguish between good and poor performing Indian FMCG companies to indicate the areas of improvement for the poor performers and suggesting strategies for improvement. The performance separation is carried out using multiple discriminant analysis technique. Top five and bottom five companies are selected on the basis of their net profit after taxes and the overall discriminant model is developed considering all possible financial variables. The developed equation satisfactorily divides companies into 2 groups, performance wise. It further identifies the key financial variables responsible for the performance. This study provides a benchmark to poor FMCG performers highlighting the possible areas of improvement. This study is limited to Indian FMCG sector only. Thus, the model cannot beapplied to evaluate sustainable performance outside the scope of this study. This study concentrates in finding out the relative performance of Indian FMCG companies. It can help companies to analyze their position in the market with respect to their competitors. This study can also be helpful for investors to identify their potential investment avenue. The study involves developing a discriminant model that separates Indian FMCG companies, performance wise using the latest data available. The developed equation can be generalized to any company related to the Indian FMCG sector to know the relative position of the particular company with respect to its competitors.
\end{abstract}

Key words: Market sustainability, discriminating model, discriminant analysis, Indian FMCG sector, respect, particular, equation

\section{INTRODUCTION}

Sustainability performance evaluation for any institution is necessary to look upon where it stands in the market to identify and rectify any feeble areas to decide the future growth strategies and to attract investors and ensuring them with good returns. An attempt to evaluate the sustainability performance of Indian FMCG companieshas been made in this study.

The FMCG sector was chosen primarily because of its contribution to Indian economy. FMCG sector is characterized by production of consumer goods that are high in volume and fetch low margins to its producers. In past couple of years Fast-Moving Consumer Goods (FMCG) industry has become a significant contributor to economy. It has made a whooping double digit growth in sales. Identified by a healthy distribution network, strong existence of MNCs, neck to neck competition between all of its segments and striving to reduce operational costs. The FMCG sector has grown at an annual average of about $11 \%$ over the last decade. Fourth, largest by market size FMC G captured US\$13.1 billion market in 2015 and is still growing. Food products is the leading segment, accounting for $43 \%$ of the overall market. Personal care $(22 \%)$ and fabric care $(12 \%)$ come next in terms of market share. The Government of India's policies and regulatory frameworks such as relaxation of license rules and approval of $51 \%$ Foreign Direct Investment (FDI) in multi-brand and $100 \%$ in single-brand retail are some of the major growth drivers for the consumer market.

Consumers of this sector mostly comprises of middle class, some what of upper middle class and few of economically disadvantaged class with an anticipated spending to surpass double that of today by 2025 . FMCG product spectrum include products which are purchased often and has low purchase cost and a low risk. The most common in the list are toilet soaps, detergents, shampoos,

Corresponding Author: L. Philo Daisy Rani, Department of Management Studies, National Institute of Technology, Periyar University, Salam, Triuchirappalli, Tamil Nadu, India 
toothpaste, shaving products, shoe polish, packaged foodstuff and household accessories and extends to certain electronic goods. These items are meant for daily of frequent consumption and have a high return.

Around 70 companies listed in SEBI were ranked according to their net profit after tax. From the listing, top five and bottom five companies were chosen for the discriminant analysis. A past data for the selected ten companies from 2011-2016 was collected from money control (2017). A multiple discriminant analysis was then performed on the data and discriminant scores were calculated. From the results obtained companies segregated as good performing and bad performing companies. Scope of this study wasto analyze to ten companies for a period of 5 years. Not all but selected financial variables were used to measure performance. Main focus of the study was to find discriminating variables and discriminating scores to separate good performing companies from poor performing companies.

Literature review: Evaluating financial performance of companies is a classical practice. Many research works used various methods to evaluate the performance of companies and thus, created a platform for this study.

Beaver (1966) collected the data of financial ratios of failed firms and compared it with the data collected of the successful firms. A conclusion made from the study was that the financial ratios for failed company had the ability to predict failure 5 years before failure. In the study, each ratio was individually analyzed and a particular value was selected to classify a company as failed or successful. This technique was termed as classification analysis technique and it was a univariate technique. Altman (1968) used Multiple Discriminant Analysis (MDA). Technique used in the analysis was multivariate. It used a discriminating variable which calculated a discriminating score for a particular financial ratio. Summing up all the discriminating scores for a company gave discriminating score that company. Based on this score a company was classified as good performing or poor performing.

Above study was restricted to individual performance of a firm in coming years more researchers contributed to find out the impact of financial ratios on market value. Ou and Penman firstly, used statistical procedures and discovered the relationship between stock returns and financial ratios. Holthausen and Larcker (1992) took this study a step further by identifying value relevant factors. Riahi-Belkaoui (1997) went even further to discover empirical relation between financial ratios to equity valuation both conditional to inflation rate and non-conditional. Bagchi et al. (2012) explored about how profitability of FMCG firms is affected by working capital management decisions. Various components of working capital like cash conversion cycle, age of inventory, age of debtors, age of creditors, debt to total assets and debt equity ratio were analyzed for the period of 2000-2001 to 2009-2010. Methods employed for the study were pearson's correlation analysis, pooled OLS Model for panel data regression and fixed effect LSDV Model. Bal (2015) applied Altman's z score to foretell whether a selected FMCG company is going to be bankrupt or not. It initiated with collection of data for the years 2011-2015 for particular five FMCG companies. The Z-score was applied to liquidity ratios and it was suggested that investors should analyze financial position of a company using the model before investing. The study concluded that all the selected companies were in sound financial position and a suggestion was made to regularly estimate Z-score strategically to retain the financial position. Mahesh and Kumar (2016) studied companies listed in NSE from FMCG sector for the period of 2004-2005 to 2014-2015. Top six companies having their total assets above Rs. 1000 crores and net profit greater than Rs. 300 crores were studied. Various mathematical and statistical tools were used in the study as CAGR, ratio ranking and Altman's Z-score. After this evaluation companies were ranked and a suggestion was made to investors. This study aims to develop a discriminant model using the latest data available. The formulated model can be generalized to any company that belongs to Indian FMCG sector.

\section{MATERIALS AND METHODS}

The aim of this study is to differentiate the performances of companies. Multiple discriminant analysis technique is used to carry out this differentiation. Discriminant analysis predicts group membership from the set of metric independent variables. These are the key financial variables of the respective companies. The weighted sum of the independent variables (financial variables in this case) will predict the discriminant score for a particular company. This discriminant score is compared with the cutting score. If greater than cutting score the company is performing well and if less than cutting score then company is not performing well. The discriminant score (unstandardized) or Z-score for a company is expressed as:

$$
\mathrm{Z}_{\mathrm{k}}=\mathrm{a}+\mathrm{W}_{1} \mathrm{X}_{1 \mathrm{k}}+\mathrm{W}_{2} \mathrm{X}_{2 \mathrm{k}}+\ldots,+\mathrm{W}_{\mathrm{n}} \mathrm{X}_{\mathrm{nk}}
$$

Where:

$\mathrm{Z}_{\mathrm{k}}=$ Discriminant $\mathrm{z}$ score for company $\mathrm{k}$

$\mathrm{a}=$ intercept

$\mathrm{W}_{\mathrm{i}}=$ Raw discriminant weight for financial variable $\mathrm{i}$

$\mathrm{X}_{\mathrm{ik}}=$ Financial variable $\mathrm{i}$ for company $\mathrm{k}$ 


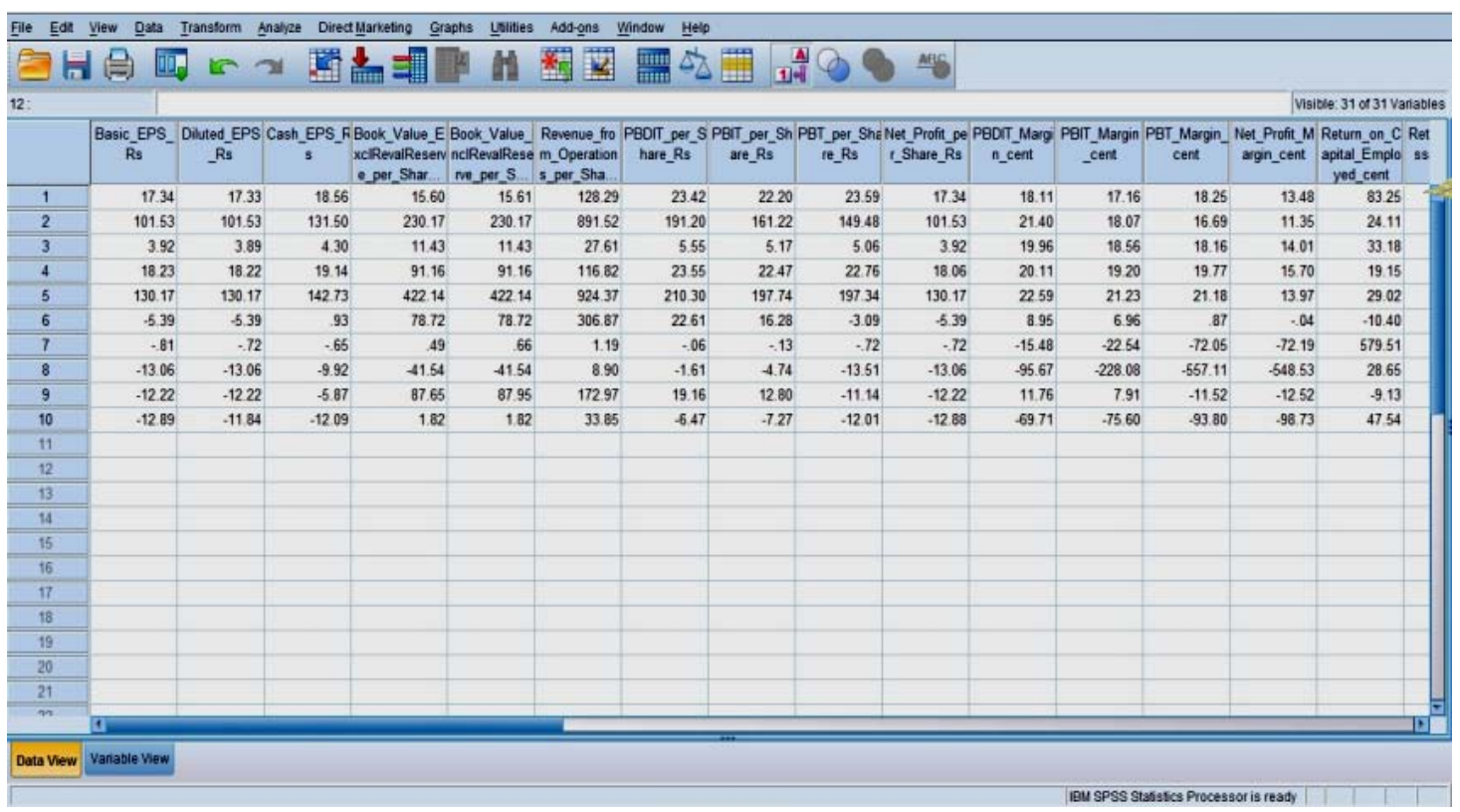

Fig. 1: A data sheet prepared in IBM SPSS showing financial variables of ten selected companies

Table 1: Ranking FMCG companies according to average net profit after tax

\begin{tabular}{lcccrrrr}
\hline Companies & $2016-2015$ & $2015-2014$ & $2014-2013$ & $2013-2012$ & $2012-2011$ & Average & Ranking \\
Hindustan Unilever & 4082.37 & 4315.26 & 3867.49 & 3796.67 & 2691.40 & 3750.640 & 1 \\
Nestle India & 563.27 & 1184.69 & 1117.13 & 1067.93 & 961.55 & 978.910 \\
Dabur India & 939.51 & 762.58 & 672.10 & 590.98 & 463.24 & 685.682 & 2 \\
Godrej Consumer & 739.72 & 654.45 & 564.84 & 510.94 & 604.39 & 614.870 & 4 \\
Glaxo Smith CHL & 686.91 & 583.60 & 674.75 & 436.76 & 355.21 & 547.450 & 5 \\
Usher Agro & -299.14 & 63.04 & 45.36 & 42.33 & 35.42 & -22.598 & 5 \\
Farmax India & -9.78 & -2.10 & -8.84 & -127.32 & 2.87 & -29.034 & 4 \\
Agro Dutch Industries & -71.03 & -77.44 & -62.39 & -99.86 & -14.06 & -64.956 & 3 \\
Lakshmi Energy and Foods & -90.78 & -336.40 & -3.43 & - & 10.77 & -104.960 & 2 \\
REI Agro & -1076.14 & -5494.30 & -38.35 & 211.01 & 226.23 & -1234.310 & 1 \\
\hline
\end{tabular}

In unstandardized method raw discriminant weights are multiplied with financial variables and the intercept is used to adjust for the means. In the current study around 70 companies listed in SEBI were arrangedin descending order according to their net profit after tax. From the obtained rankings top five and bottom five companies were chosen to formulate the discriminant model (Table 1). Past data for the selected ten companies from 2011-2016 was retrieved from Stock Market India: Sector Info: Company Info (2017) Money Control: http://www.moneycontrol.com/.

In general, the discriminant analysis can be carried out using one of the two methods, simultaneous/direct estimation or stepwise estimation.

Simultaneous estimation: Simultaneous or direct estimation considers all the independent variables at a time. The formulated model with this estimation will compute the discriminant score including all the considered variables, regardless of the fact that whether the variable makes any significant contribution to discrimination or not.
Stepwise estimation: This method formulates model by considering the independent variables one by one based on their discriminating power. In this study stepwise estimation method is selected as it stresses on including variables having high discrimination power and ignores the non-contributing variables.

The discriminating power is calculated by the discriminating weight a variable has irrespective of sign, the magnitude of the discriminating weight states how much it contributes to the discriminating power. Sign conveys whether the variable is making positive or negative contribution (Fig. 1).

The stepwise process starts with selecting the best discriminating variable. This selected variable is then paired with available variables. The pairing variable which improves the discrimination is selected next. Any variable not improving the solution at any stage of the formulation process is removed from the model. This process continues until no variable is left that has considerable discriminating power. All excluded variables are assumed to have no significant contribution in the 
discrimination. After the modeling of discriminant function and calculation Z-scores for companies, cut off score or critical Z-value is calculated. Cutting score will divide companies into respective groups.

Data for thirty financial variables along with one grouping variable was collected. With the help of this data individual Z-score, cut off score and group classification is calculated (Fig. 1). IBM SPSS is used to carry out calculations. Results of this calculations are discussed in the next section.

\section{RESULTS AND DISCUSSION}

The results obtained after performing discriminant analysis are: the data in this study is classified into two groups, thus there will be single discriminant function. The difference is group means is divided by standard deviation to get effect size of a discriminant function. This effect size is a measure of group differences used to calculate statistical power. The effect size of this discriminant function is given by squared canonical correlation which is $(0.956)^{2}=0.914$ (Table 2).

The Wilk's Lambda represents how well the given function discriminates (Table 3). The lower lambda value here suggests that this discriminating function classifies data satisfactorily. Also with $9.816 \chi^{2}$-value and $0.278 \mathrm{Sig}$. the function is statistically significant to discriminate.

Table 3 shows the variables constituting the function. Out of thirty independent variables only eight variables are contributing remarkably to discrimination (Table 4). Using table the discriminating function can be written as:

$$
Z_{\mathrm{k}}=(0.105) \times \text { Basic EPS }+(0.256) \times
$$

Cash EPS $+(-0.024) \times$ Book value per share $+(0.04) \times$

Revenue from operations per share $+(-0.22) \times$

PBDIT per share $+(-0.011) \times$

Asset turnover ratio $+(4.828) \times$ Current Ratio $+(0.083) \times$

Earnings Yield $+(-1.829)$

The function centroids are mentioned in Table 5. These are the average discriminant scores for each group. Good performing companies have group centroid at $2.917 \mathrm{Z}$-score and poor performing companies have group centroid at $-2.917 \mathrm{Z}$-score. Centroids can be useful for plotting groups on graph and analyzing group membership graphically.

The structure matrix given by Table 6 , contains all the independent variables. This matrix represents the correlations between financial variables and discriminating function. More the correlation, more will be the discriminating power of that financial variable. Only eight of the thirty variables have been chosen. This is due to the multicollinearity present between them. Some

Table 2: Canonical correlation of discriminant function

\begin{tabular}{lcccc}
\hline Function & Eigen value & Variance (\%) & Cumulative (\%) & $\begin{array}{c}\text { Canonical } \\
\text { correlation }\end{array}$ \\
\hline 1 & $10.635^{\mathrm{a}}$ & 100.0 & 100.0 & 0.956 \\
\hline
\end{tabular}

First 1 canonical discriminant functions were used in the analysis

Table 3: Wilk's Lambda value for the discriminant function

\begin{tabular}{lllll}
\hline Test of function(s) & Wilks Lambda & Chi-square & df & Sig. \\
\hline
\end{tabular}

\begin{tabular}{lllll}
\hline 1 & 0.086 & 9.816 & 8 & 0.278 \\
\hline
\end{tabular}

$\underline{\text { Table 4: Unstandardized canonical discriminant function coefficient }}{ }^{*}$

\begin{tabular}{lc}
\hline Classify & Function 1 \\
\hline Basic_EPS_Rs & 0.105 \\
Cash_EPS_Rs & 0.256 \\
Book_Value_ExclRevalReserve_per_Share_Rs & -0.024 \\
Revenue_from_Operations_per_Share_Rs & 0.004 \\
PBDIT_per_Share_Rs & -0.220 \\
Asset_Turnover_Ratio_cent & -0.011 \\
Current_Ratio & 4.828 \\
Earnings_Yield & 0.083 \\
(Constant) & -1.829 \\
\hline
\end{tabular}

*Unstandardized coefficients

Table 5: Functions at group centroids

\begin{tabular}{lc}
\hline Classify & Function 1 \\
\hline Poor & -2.917 \\
Good & 2.917 \\
\hline
\end{tabular}

Unstandardized canonical discriminant functions evaluated at group means

Table 6: Structure matrix

\begin{tabular}{|c|c|}
\hline Classify & Function 1 \\
\hline Return_on_Capital_Employed_cent ${ }^{\mathrm{a}}$ & 0.744 \\
\hline EV_per_EBITDA ${ }^{a}$ & 0.721 \\
\hline Return_on_Assets_cent ${ }^{\mathrm{a}}$ & -0.698 \\
\hline PBIT_Margin_cent ${ }^{\mathrm{a}}$ & 0.502 \\
\hline PBT_Margin_cent ${ }^{\mathrm{a}}$ & 0.487 \\
\hline Net_Profit_Margin_cent ${ }^{\mathrm{a}}$ & 0.487 \\
\hline PBDITIMargin_cent ${ }^{\mathrm{a}}$ & 0.408 \\
\hline EV_per_Net_Operating_Revenue ${ }^{a}$ & -0.401 \\
\hline Asset_Turnover_Ratio_cent & 0.376 \\
\hline Quick_Ratio $^{\mathrm{a}}$ & 0.356 \\
\hline Inventory_Tumover_Ratio ${ }^{a}$ & 0.308 \\
\hline Net_Profit_per_Share_Rs ${ }^{\mathrm{a}}$ & 0.266 \\
\hline Basic_EPS_Rs & 0.265 \\
\hline Diluted_EPS_Rs ${ }^{a}$ & 0.265 \\
\hline PBT_per_Share_Rs ${ }^{\mathrm{a}}$ & 0.249 \\
\hline Cash_EPS_Rs & 0.245 \\
\hline PBIT_per_Share_Rs ${ }^{\mathrm{a}}$ & 0.210 \\
\hline PBDIT_per_Share_Rs & 0.200 \\
\hline MarketCap_per_Net_Operating_Revenue ${ }^{a}$ & -0.180 \\
\hline Price_per_Net_Operating_Revenue ${ }^{a}$ & -0.179 \\
\hline Current_Ratio & 0.179 \\
\hline Book_Value_IncIRevalReserve_per_Share_Rs ${ }^{\mathrm{a}}$ & 0.171 \\
\hline Book_Value_ExclRevalReserve_per_Share_Rs & 0.171 \\
\hline Earnings_Yield & 0.165 \\
\hline Enterprise_Value_Cr ${ }^{\mathrm{a}}$ & -0.163 \\
\hline Revenue_from_Operations_per_Share_Rs & 0.162 \\
\hline Price_per_BV ${ }^{a}$ & -0.084 \\
\hline Cash_Eamings_Retention_Ratio_cent ${ }^{\mathrm{a}}$ & 0.046 \\
\hline Retention_Ratios_cent ${ }^{\mathrm{a}}$ & 0.008 \\
\hline Earnings Retention Ratio cent ${ }^{\mathrm{a}}$ & 0.008 \\
\hline
\end{tabular}


Table 7: Group classification matrix; Predicted group membership

\begin{tabular}{|c|c|c|c|}
\hline \multirow[b]{2}{*}{ Classify (original) } & \multicolumn{2}{|c|}{ Predicted group membership } & \multirow[b]{2}{*}{ Total } \\
\hline & 0 & 1 & \\
\hline \multicolumn{4}{|l|}{ Count } \\
\hline 0 & 5 & 0 & 5 \\
\hline 1 & 0 & 5 & 5 \\
\hline \multicolumn{4}{|l|}{ Percentage } \\
\hline 0 & 100.0 & 0.0 & 100.0 \\
\hline 1 & 0.0 & 100.0 & 100.0 \\
\hline
\end{tabular}

variable combinations worsen the discrimination and thus should be avoided. Stepwise estimation provides best discriminating function step by step using and testing various variable combinations.

The group classification matrix represents the accuracy of classification of the individual company into respective group, based on the grouping variable. The grouping variable here is net profit after tax. The results in Table 7 shows that companies are perfectly classified.

For any FMCG company other than the selected if the discriminating score is positive it is performing well and otherwise it is not performing well.

\section{CONCLUSION}

The study started with choosing five top most and five bottom most companies in the Indian FMCG sector on the basis of net profit after tax. Multiple discriminant analysis was then performed on the previous data of these companies using IBM SPSS. An equation was formed after analysis which classified companies from the FMCG sector as good performing or poor performing based on their individual score. Investors can check if their potential investment avenue from FMCG sector is performing well or not by calculating the discriminating score with available data. Also, the poor performing companies may consider the variables such as basic EPS, cash EPS, etc. which are in the discriminant equation and contributing majorly to the performance. Improving these variables can result in overall performance enhancement for the poor performing companies. This study is only restricted to FMCG sector in future an attempt will be made to widen the scope of study to cover entire market.

\section{REFERENCES}

Altman, E.I., 1968. Financial ratios, discriminant analysis and the prediction of corporate bankruptcy. J. Finance, 23: 589-609.

Bagchi, B., J. Chakrabarti and P.B. Roy, 2012. Influence of working capital management on profitability: A study on Indian FMCG companies. Intl. J. Bus. Manage., 7: $1-10$.

Bal, G.R., 2015. Prediction of financial distress using altman z-score: A study of select FMCG companies. Indian J. Appl. Res., 5: 129-131.

Beaver, W.H., 1966. Financial ratios as predictors of failure. J. Account. Res., 4: 71-111.

Holthausen, R.W. and D.F. Larcker, 1992. The prediction of stock returns using financial statement information. J. Accounting Econ., 15: 373-411.

Mahesh, N.M. and S.S. Kumar, 2016. Fundamental analysis of selected Indian FMCG companies listed in nse of India limited. Indian J. Appl. Res., 6: 695-698.

Riahi-Belkaoui, A., 1997. Value relevance of popular financial ratios. Adv. Quant. Anal. Finance Accounting, 5: 193-201. 